\title{
Fatores que influenciam a intenção de compra de viagens de ecoturismo e turismo de aventura ${ }^{1}$
}

\author{
Factors influencing intention to purchase ecotourism and \\ adventure tourism trips
}

\author{
Leandro Augusto Gouveia, Marlusa Gosling, Mariana de Freitas Coelho, \\ Gisele de Araujo Pereira
}

\begin{abstract}
RESUMO
O crescimento do mercado turístico brasileiro e o interesse do consumidor pela prática de turismo de aventura e ecoturismo (BRASIL, 2012a) torna pertinente a investigação acerca do comportamento do turista como consumidor de produtos e serviços. Assim, conhecer as variáveis de influência sobre o comportamento de compra do turista é importante para que as empresas possam orientar suas ofertas para o mercado e qualificar seus produtos e serviços de acordo com os desejos e as necessidades do consumidor (ENGEL; BLACKWELL; MINIARD, 2000). Para que seja possível entender o processo decisório de um serviço tão complexo quanto o turismo é preciso considerar os fatores internos e externos ao indivíduo que influenciam essas decisões (SWARBROOKE; HORNER, 2002). Para isso, este trabalho teve como objetivo identificar os principais fatores que influenciam a intenção de compra do turista de aventura e ecoturismo, fundamentando-se no modelo de Estímulo-Resposta do Comportamento do Consumidor de Middleton (1994). O trabalho utilizou-se de metodologia qualitativa e exploratória, entrevistando 10 indivíduos da cidade de Belo Horizonte que costumam efetuar viagens com propósitos de ecoturismo e turismo de aventura. De acordo com os resultados encontrados, os principais fatores que influenciam o comportamento de consumo desses turistas são: os grupos de referência, a imagem que o indivíduo tem de determinado destino e a possibilidade de contato com o meio ambiente. Além disso, o estudo apontou a preferência por viagens organizadas de maneira independente em detrimento das organizadas por agências, principalmente pelos consumidores mais jovens entrevistados, devido à importância aferida à liberdade e a flexibilidade durante esse tipo de viagem.
\end{abstract}

PALAVRAS-CHAVE: Comportamento do Consumidor; Ecoturismo; Turismo de Aventura; Processo Decisório. 


\begin{abstract}
The growth of the Brazilian tourism market and the interest about adventure tourism and ecotourism practices from the consumer (BRASIL, 2012a) make pertinent an investigation about the tourism behavior as a products and services consumer. Therefore, knowing the variables of influence about the tourist buying behavior is important because companies can steer their offerings to market and qualify their products and services according to the desires and needs of consumers (ENGEL; BLACKWELL; MINIARD, 2000). To be able to understand the decision-making process of a service as complex as tourism is necessary to take into account internal and external factors to the individual that influence these decisions (SWARBROOKE; HORNER, 2002). To achieve this, this paper aimed at identifying the main factors that influence the purchase intention of the ecotourism and adventure tourists. The research is based on the Stimulus-Response of Consumer Behavior Model, proposed by Middleton (1994). The study used a qualitative and exploratory methodology, interviewing 10 individuals from the city of Belo Horizonte who usually make trips for purposes of ecotourism and adventure tourism. According to the results, the main factors that influence consumer behavior in adventure tourism and ecotourism are: reference groups, the image that the individual have of a certain destination, the interest in sports practices and contact with the environment. In addition, the study showed a preference for independent travel rather than trips organized by agencies, especially by younger consumers surveyed, due to the importance they give for freedom and flexibility for this kind of trip.
\end{abstract}

KEYWORDS: Consumer Behavior; Ecotourism; Adventure Tourism; Decision-making Process.

\title{
Introdução
}

Conhecer as variáveis de influência sobre o comportamento de compra dos indivíduos é importante para que os empresários possam qualificar seus produtos e serviços e orientar suas ofertas ao mercado, de acordo com os desejos e as necessidades do consumidor (ENGEL; BLACKWELL; MINIARD, 2000).

Uma das possibilidades de compra que merece investigação é o comportamento do turista, que cada vez mais tem buscado sair de sua rotina e ter contato com locais fora do seu local de moradia. Segundo ElenaNicoleta (2009), analisar o comportamento do turista é mais difícil porque a decisão de compra envolve fatores emocionais subjetivos, e não necessariamente fatores econômicos.

A busca pela compreensão do comportamento do turista é um tema que merece reflexões e que ainda apresenta poucos estudos empíricos, principalmente com foco nos turistas brasileiros. Para que seja possível entender o processo decisório de um serviço tão complexo quanto o turismo é preciso considerar os fatores internos e externos que influenciam essas decisões (SWARBROOKE; HORNER, 2002), já que uma enorme variedade 
de influências afeta os indivíduos ao longo do tempo (BERGIN-SEERS; MAIR; 2009).

O Diagnóstico do Turismo de Aventura (ABETA; BRASIL, 2009) descreve que a oferta do turismo de aventura no Brasil é incipiente em relação à padronização da qualidade dos serviços quando comparado a outros países que também oferecem atividades no segmento, porém, apresenta diversidade e atratividade dos recursos naturais. Segundo TorresSovero et al. (2012), o ecoturismo representa uma fatia pequena do turismo global, mas que vem crescendo significativamente.

Este trabalho é justificado pelo crescimento da atividade turística no Brasil e pelo aumento da intenção de viagem dos brasileiros (BRASIL, 2012a; 2013). Ainda, pela relevância da atividade turística para a utilização do tempo livre, que demanda a investigação de segmentos específicos (SOUSA; SIMÕES, 2010) como o turismo de aventura e o ecoturismo, os quais enfatizam o contato com a natureza e envolvem a sustentabilidade local (MERCE et al., 2012).

O estado de Minas Gerais é terceiro principal estado de origem de turistas domésticos no Brasil, com $8 \%$ do total, estando atrás apenas de São Paulo (22,5\%) e Rio de Janeiro (8,6\%) (BRASIL, 2012b). Assim, percebe-se a relevância de um maior aprofundamento acerca dos fatores que interferem na escolha dos destinos de aventura e ecoturismo, sobretudo nos grandes centros emissores de turistas, como Minas Gerais, representado pela sua capital Belo Horizonte.

Diante do exposto, o presente estudo tem como principal objetivo identificar os principais fatores que influenciam a intenção de compra dos consumidores residentes em Belo Horizonte, quanto à compra de viagens de turismo de aventura e ecoturismo. Além disso, o estudo também busca averiguar a preferência dos turistas entre viagens de ecoturismo e turismo de aventura através de agência de viagem ou viagem independente.

\section{Referencial teórico}

\section{O ecoturismo e o turismo de aventura}

Dada a importância da atividade turística para a utilização do tempo livre, este trabalho volta suas atenções para estes segmentos turísticos específicos: o turismo de aventura e o ecoturismo. Essas atividades enfatizam o contato com a natureza e a fuga da rotina, ao contrário de outras tipologias turísticas como o Turismo de Eventos, o Turismo de Negócios e o Turismo Religioso.

O turismo baseado na natureza vem se tornando popular em todo o mundo, uma vez que visa promover benefícios econômicos advindos da conservação dos recursos naturais e o desenvolvimento sustentável tanto do meio ambiente quanto das comunidades envolvidas (LEE, 2009). Desde a década de 1980, várias reflexões foram realizadas sobre o turismo de aventura que, assim como o ecoturismo, são pautados pela mudança na mentalidade dos consumidores e operadores turísticos a respeito da importância da sustentabilidade (LEE, 2009). 
Apesar de não haver consenso na definição de ecoturismo e turismo de aventura, entende-se que são que conceitos relacionados. Uma das formas de entender a relação entre os dois conceitos é classificá-los como segmentos pertencentes a uma tipologia turística mais ampla, o turismo de natureza. Para Lee (2009, p.216, grifo nosso) o turismo de natureza é visto como "um sinônimo de programas de turismo alternativo, ecoturismo, turismo verde, turismo responsável, soft-turismo, turismo cultural e de aventura". Outro ponto em comum de ambos segmentos destacado por Lee (2009) é possibilidade de promover benefícios econômicos advindos da conservação dos recursos naturais e o desenvolvimento sustentável tanto do meio ambiente quanto das comunidades envolvidas (LEE, 2009).

Sobre as especificidades de cada conceito, Fennel (1999, p.46) define o ecoturismo como:

O turismo na natureza, de baixo impacto, que contribui à manutenção de espécies e habitats diretamente, por meio de uma contribuição à conservação e/ou indiretamente produzindo rendimentos para as comunidades locais, para que elas valorizem e, portanto, protejam suas áreas herdadas de vida selvagem como fonte de renda.

Uma possível reflexão sobre como as experiências do turismo de aventura e do ecoturismo diferem-se está situada no campo da psicologia social, que estuda o motivo pelo qual ocorre a participação de um ponto de vista cognitivo e comportamental. Ewert (1985) e Hall (1992) afirmam que o fator mais importante na decisão de alguém em se engajar em atividades de aventura é o risco. Além disso, Hall (1992) sugere que a atração dominante para a procura da recreação e do turismo de aventura está muito mais relacionada à atividade do que ao local.

Segundo o Ministério do Turismo, Brasil (2008, p.39) "Turismo de Aventura compreende os movimentos turísticos decorrentes da prática de atividades de aventura de caráter recreativo e não-competitivo". As práticas de aventura de caráter recreativo e não competitivo "pressupõem determinado esforço e riscos controláveis, e que podem variar de intensidade conforme a exigência de cada atividade e a capacidade física e psicológica do turista" (Brasil, 2008, p.41). É válido, destacar, no entanto, que há a possibilidade de desenvolver atividades de aventura em ambientes artificiais, sem o contato direto com a natureza.

De outra forma, o ecoturismo é definido pelo Ministério do Turismo, Brasil (2008, p.9) como:

(...) o segmento da atividade turística que utiliza, de forma sustentável, o patrimônio natural e cultural, incentiva sua conservação e busca a formação de uma consciência ambientalista por meio da interpretação do ambiente, promovendo o bem-estar das populações. 
Pires (1998) também destaca que há diferenças no entendimento conceitual do termo ecoturismo conforme os atores associados à atividade, sendo eles, o trade turístico, a área governamental, as populações residentes nos destinos, os turistas e o meio acadêmico, e outros. Para o autor, "o público tende a emitir um conceito mais simplista e até mesmo emotivo sobre o ecoturismo" (PIRES, 1998, p.78). Nesse sentido, a experiência do turista também interfere na maneira como ele entende a atividade.

São atividades características do ecoturismo: a observação e contemplação da fauna, da flora e das formações geológicas, além da realização caminhadas, mergulhos, safáris fotográficos e trilhas interpretativas, entre outros. Para Swarbrooke e Horner (2002, p.300) "o ecoturista é alguém cujo principal motivo para viajar é ver a vida selvagem e as comunidades em seu habitat natural', o que casa com as definições apresentadas anteriormente sobre ecoturismo.

Já em relação ao turista de aventura, Swarbrooke et al. (2003, p.56), trazem uma definição mais abrangente. Os autores dizem que "embora 0 turismo de aventura se sobreponha a outros tipos de turismo", como o ecoturismo, os turistas de aventura:

(...) têm uma série de atributos distintivos que os distinguem de outros mercados turísticos. Eles geralmente assumem riscos e buscam desafios mentais ou físicos, procuram novidade e experiências estimulantes, eles às vezes envolvem-se em aventura para o desenvolvimento pessoal ou razões de autoestima. (SWARBROOKE et al., 2003, p.57)

Nesse sentido, Swarbrooke et al. (2003) definem o turismo de aventura em uma perspectiva que ultrapassa a tipologia do turismo de natureza e da prática de atividades que requerem esforço físico. Para os autores, o turista de aventura busca desafios quaisquer que sejam, independentemente de estarem relacionados a prática de atividades e ao envolvimento com a natureza.

Dadas as diversas conceituações, é importante esclarecer que neste trabalho, adotou-se a perspectiva de turismo de aventura, relacionada à prática de atividades de aventura de caráter recreativo e não-competitivo, realizada próximo à natureza. Isso porque no Brasil, segundo informa Abeta/Brasil (2009), o turismo de aventura está na maioria das vezes relacionado ao turismo de natureza.

Nesse sentido, pode-se afirmar que ambos, o turismo de aventura e o ecoturismo são pautados em iniciativas de sustentabilidade e interesse pela natureza, porém o turismo de aventura foca na atividade que proporciona aventura para o participante, enquanto o ecoturismo foca no ambiente onde a atividade é desenvolvida, isto é, tende a se desenvolver de uma maneira mais próxima ao contexto socioambiental, político e econômico onde a atividade é desenvolvida. 
Apesar de conceitualmente o ecoturismo estar relacionado a questões de sustentabilidade e desenvolvimento socioeconômico e cultural, segundo o estudo de Torres-Sovero et al. (2011) apenas uma fatia pequena são "verdadeiros ecoturistas", ou seja, buscam esse tipo de atividade, pois são plenamente conscientes e engajados com a causa. $O$ estudo identificou que muitos têm interesses em biodiversidade, culturas locais e/ou aventura, mas o grau de satisfação dos mesmos não está positivamente correlacionado com essas atividades, ou seja, vários outros fatores influenciam mais fortemente a satisfação, além da real atividade ecoturística, revelando a existência de uma variedade de tipologias dos (eco) turistas.

Chiu et al. (2013) identificaram que apesar da fatia dos verdadeiros ecoturistas ser pequena, é possível influenciar o comportamento ambientalmente responsável dos turistas quando esses ficam satisfeitos com a sua experiência de turismo. Os autores concluíram que o valor percebido pelos turistas os influencia a desenvolver um relacionamento mais forte com o ecoturismo e, por consequência, com um comportamento mais ambientalmente responsável. O que se relaciona diretamente com a ideia de Mowforth (1993) de que o ecoturismo deve-se diferenciar do turismo tradicional pela introdução de um componente educacional.

Além disso, conforme mostra Pires (1998), a rotulação "eco" associada a bens consumíveis, também vem sendo relacionada ao turismo tradicional. O que faz com que muitas vezes o teor ecológico da atividade seja muito mais propagandístico do que real.

Parece existir uma lacuna entre os reais objetivos do ecoturismo e turismo de aventura e o que é vendido pelos promotores de atividades turísticas. Além de haver diferenças também entre os objetivos das diferentes tipologias de (eco) turistas. Contudo, o que se pretende entender neste trabalho é o que influencia o turista a optar por opções de lazer relacionadas ao que se tem rotulado como ecoturismo e turismo de aventura, independente de ser esse um "verdadeiro ecoturista" participando de um "verdadeiro destino ecoturístico" ou não.

\section{Comportamento do consumidor no turismo}

O turismo é uma das atividades que podem ser analisadas a partir dos estudos a respeito do comportamento do consumidor. Isso porque, a atividade turística também passa por estágios que vão desde o processo decisório até o pós-compra de forma semelhante ao que ocorre nas atividades de consumo em geral. Ademais, a atividade turística pode ser considerada uma atividade de lazer, como forma de preenchimento do tempo livre, permitindo a troca sociocultural que interfere no processo de aprendizagem com a experiência do turista consumidor.

Por isso, identificar e analisar os fatores que contribuem para a escolha por viagens que priorizam o contato com a natureza, no caso do turismo de aventura e ecoturismo, é importante para possibilitar a criação de opções de compra que sejam capazes de suprir os desejos e necessidades dos turistas. 
Vários modelos já foram elaborados com o objetivo de explicar o comportamento do consumidor desde o estágio de decisão até o póscompra no turismo. Ao optar por um pacote turístico, o consumidor gera uma expectativa e investe na compra de produtos e serviços que são essencialmente intangíveis. Percebe-se, então, que os modelos de comportamento do consumidor voltados para o turismo deveriam levar em consideração a característica intangível do setor, além do fato de que a aquisição de um serviço não resulta na posse efetiva de um produto.

Dentre os diversos modelos que buscam explicar o comportamento do consumidor em turismo, pode-se citar: os modelos de Wahab, Crompton e Rothfield (1976), Schmoll (1977) e Mathiesson e Wall (1992). Esses modelos, embora tenham sido relevantes, apresentam um processo de decisão linear e lógico, sem levar em consideração fatores não planejados que podem ser primordiais durante uma tomada de decisão.

Já os modelos de Moutinho (1987) e Gilbert (1991) trazem questões um pouco mais abrangentes. Moutinho (1987) cita estágios distintos do processo de tomada de decisão, além disso, o autor observa que as decisões de compra resultam de três conceitos comportamentais: motivação, cognição e aprendizado. Já Gilbert (1991), inclui influências psicológicas, como percepção, aprendizado e influências sociais promovidas pelos grupos de referências e família.

Percebe-se que os modelos de Moutinho (1987) e Gilbert (1991) trazem ideias semelhantes às de Churchill e Peter (2000) e Kotler (2006) a respeito do comportamento do consumidor. Churchill e Peter (2000, p.160) citam que os grupos de referência são "grupos de pessoas que influenciam os pensamentos, os sentimentos e os comportamentos do consumidor", e Kotler (2006) os define como todos aqueles que exercem alguma influência direta ou indireta sobre as atitudes ou o comportamento de uma pessoa. Além disso, Kotler (2006) também aponta os fatores psicológicos que influenciam as decisões de compra como motivação, percepção, aprendizagem e memória.

Buscando um modelo que pudesse melhor explicar o comportamento do consumidor no turismo, optou-se por basear este estudo no Modelo de Estímulo-Resposta do Comportamento do Consumidor de Middleton (1994). Isso porque, o modelo de Middleton (1994), um pouco mais abrangente que os demais, tenta abordar a complexidade do tema por meio de diversas variáveis envolvidas na influência do consumidor, propiciando uma análise mais completa e incluindo elementos intangíveis sempre presentes na atividade turística.

O modelo de Middleton (1994) utiliza quatro componentes que interagem entre $\mathrm{si}$, sendo $\mathrm{o}$ componente central identificado como "Características do comprador e processo de tomada de decisão", para explicar como acontece a decisão de compra quando se trata de turismo. Os componentes "Entrada de estímulo" e "Canais de comunicação" referemse à etapa de pré-compra, onde diversos fatores influenciam o consumidor para assumir determinado comportamento.

Já o componente central diz respeito à compra em si, que é resultado das influências anteriores somadas às características pessoais do indivíduo. 
Finalmente, o componente "Resposta de compra" está relacionado à etapa de pós-compra, ligada à experiência vivida e ao nível de satisfação atingido, que podem se transformar em filtros de comunicação para uma próxima compra. A figura 2 exemplifica o modelo:

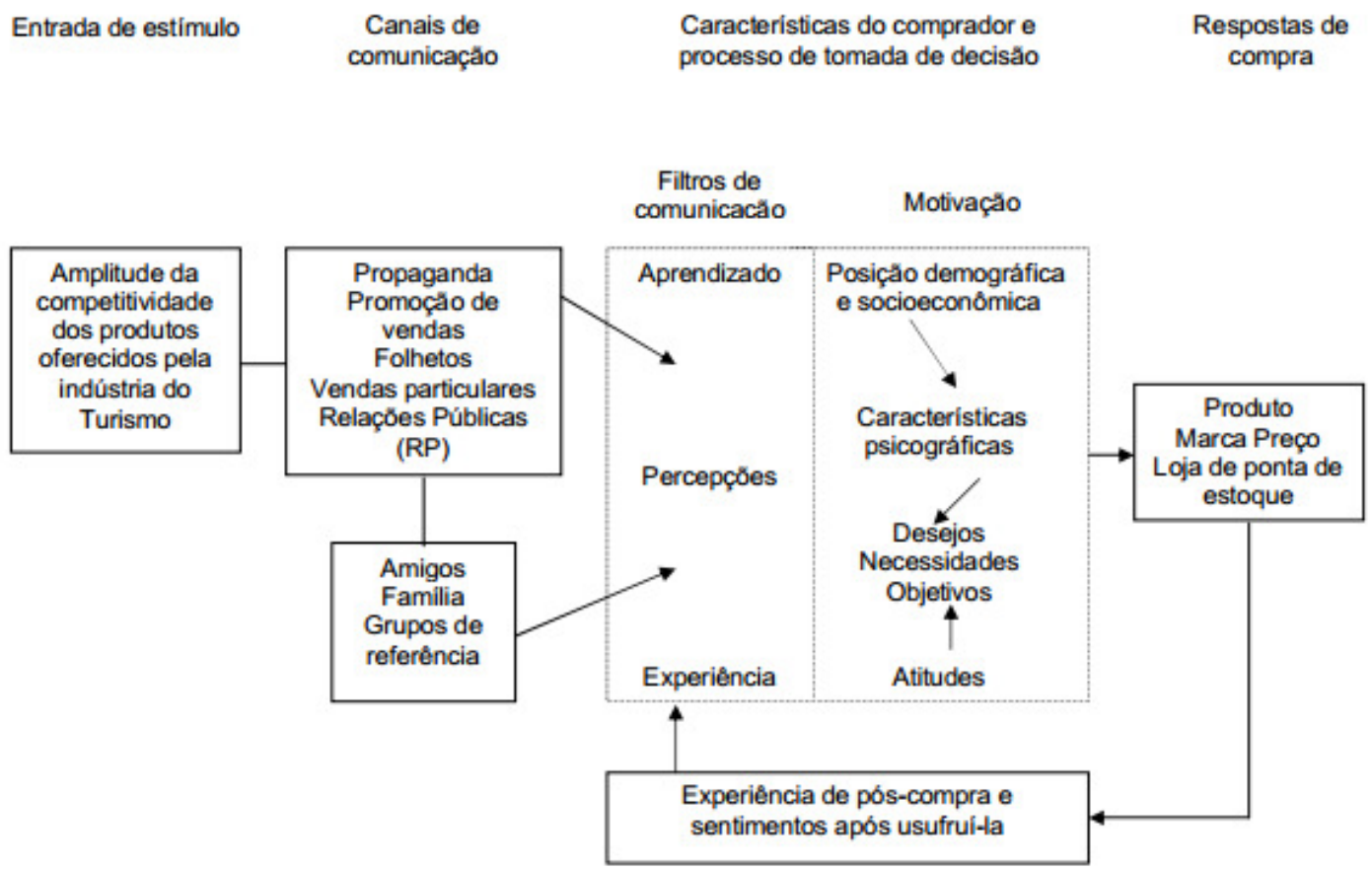

Figura 2: Modelo de estímulo-resposta do comportamento do consumidor.

Fonte: Middleton (1994).

Figure 2: Model of stimulus-response of consumer behavior.

Source: Middleton (1994).

Conhecer os fatores motivacionais que influenciam o comportamento de consumo no turismo apresentados na próxima seção, permitirá um melhor entendimento sobre porque o modelo de Middleton (1994) foi escolhido para o trabalho.

\section{Fatores motivacionais para o comportamento de consumo no turismo}

Diferentes fatores exercem influência sobre a motivação para o consumo de atividades turísticas. Mclntosh, Gooldner e Ritchie (1995) apontam quatro categorias de motivação para o turismo:

1. Motivadores físicos: relaxamento do corpo e da mente, saúde, esportes e prazer (atividades que reduzem a tensão).

2. Motivadores culturais: desejo de ver e conhecer mais sobre outras culturas e sobre as pessoas que vivem imersas nas mesmas.

3. Motivadores interpessoais: desejo de conhecer novas pessoas ou de visitar parentes e amigos como forma de escape dos relacionamentos de rotina. 
4. Motivadores de status e prestígio: desejo de reconhecimento e atenção de outros, como forma de estimular 0 ego, desenvolvimento de hobbies e atividades de educação.

Ainda, dois fatores motivacionais merecem destaque na literatura do turismo: 1) a imagem que o consumidor constrói acerca do possível destino de viagem e; 2) a influência exercida pelo ambiente do qual ele faz parte.

Sobre o primeiro fator motivacional, a imagem que o indivíduo tem de determinado local, interfere no comportamento do consumidor com relação ao turismo. De acordo com Mathieson e Wall (1996) existem diferentes fatores, tais como o perfil do turista, as características da viagem, as pressões domésticas, a confiança nos intermediários e a coleta e busca de informações, através dos quais essa imagem pode ser formada. A partir dessa imagem, os turistas em potencial fazem avaliações acerca dos lugares para onde pretendem ir. $\mathrm{O}$ desejo por uma viagem surge a partir do agrupamento de elementos referentes às características e à percepção da mesma, determinada pelas informações adquiridas pelo turista. No turismo de aventura e ecoturismo, fatores como a promessa de contato com a natureza, a possibilidade de lazer e entretenimento, e busca por uma experiência visual intensa, podem ser elementos formadores da imagem que o indivíduo possui de tais atividades.

O segundo fator motivacional envolve o ambiente no qual o indivíduo está inserido. Um exemplo de influência ambiental consiste no ambiente de trabalho do turista, que está atrelado ao cotidiano do mesmo. Ross (2002) aponta uma dicotomia acerca da influência que o ambiente de trabalho pode exercer sobre o turista em potencial. De um lado, o "Efeito Contaminação" justifica o comportamento dos turistas a partir da influência dos hábitos relacionados ao ambiente de trabalho. Por outro lado, a "Hipótese Compensatória" explica que o indivíduo compensa suas insatisfações relacionadas ao ambiente de trabalho, ou seja, busca realizar, através do consumo de turismo, vontades que não são saciadas no seu dia-a-dia profissional (ROSS, 2002). Além do trabalho, o ambiente familiar, a exposição à propagandas e contato com amigos e parceiros também podem afetar a motivação de viagem.

O turismo aparece, portanto, como uma forma de atender às expectativas do indivíduo dentro do seu contexto socioambiental. De acordo com Gnoth (1997), essas expectativas surgem a partir das emoções, do sistema de valores e das necessidades conscientes de cada um, sendo um fator de influência de grande importância durante o processo motivacional do turista.

Os fatores motivacionais citados (influência do ambiente onde determinado indivíduo está inserido e a obtenção de informações que levam à construção de uma imagem prévia do destino de viagem) podem ser percebidos dentro do Modelo de Estímulo-Resposta de Middleton (1994) (Figura 2). O modelo aborda justamente o comportamento do consumidor através da entrada de estímulo, dos canais de comunicação, das características do comprador e processo de tomada de decisão e das respostas pós-compra, sustentando a escolha do modelo para o estudo. 


\section{Metodologia}

Uma vez que existem diversos fatores que influenciam o comportamento do consumidor é necessário um rigor do método para atingir os objetivos da pesquisa. Assim, optou-se por uma pesquisa qualitativa, de caráter exploratório (MALHOTRA, 2006).

De acordo com Malhotra (2006), a pesquisa qualitativa baseia-se em amostras pequenas, proporcionando assim, uma melhor compreensão do contexto do problema. Ainda, a pesquisa exploratória é preferível quando o objetivo é a descoberta de ideias e dados, sendo necessário explorar um problema para prover critérios e compreensão (MALHOTRA, 2006).

Com o objetivo de compreender quais os principais fatores que influenciam a intenção de compra de pacotes de turismo de aventura e ecoturismo em Belo Horizonte, foram aplicadas entrevistas baseadas em um roteiro semiestruturado contendo dez questões.

Quadro 1: Roteiro semiestruturado para as entrevistas

Table 1: Semi-structured framework for interview

\begin{tabular}{|l|l|}
\hline \multicolumn{2}{|l|}{$\begin{array}{l}\text { Informações gerais: } \\
\text { Nome: } \\
\text { Sexo: } \\
\text { Idade: } \\
\text { Grau de formação: } \\
\text { Local de residência: }\end{array}$} \\
\hline 1. & $\begin{array}{l}\text { Como você começou a fazer viagens de turismo de aventura ou ecoturismo? } \\
\text { Com que frequência você viaja para esses destinos? }\end{array}$ \\
\hline 2. & $\begin{array}{l}\text { Quem são os principais influenciadores sua escolha por viagens de } \\
\text { aventura? Você normalmente viaja sozinho ou acompanhado? }\end{array}$ \\
\hline 3. & $\begin{array}{l}\text { O que é mais importante para você no momento da escolha de um pacote } \\
\text { de ecoturismo ou turismo de aventura? }\end{array}$ \\
\hline 4. & Você prefere viajar através de uma agência de viagem? Por quê? \\
\hline 5. & $\begin{array}{l}\text { Você planeja a compra de viagens de ecoturismo ou turismo de aventura? } \\
\text { De que maneira? Com que antecedência? }\end{array}$ \\
\hline 6. & $\begin{array}{l}\text { Por que você escolheu pelo turismo de aventura ou ecoturismo? O que te } \\
\text { influenciou a decidir por este tipo de viagem? }\end{array}$ \\
\hline 7. & $\begin{array}{l}\text { Como você toma conhecimento das novidades sobre viagens de } \\
\text { ecoturismo e turismo de aventura? Aonde você percebe maior divulgação } \\
\text { sobre viagens deste tipo? }\end{array}$ \\
\hline 8. & Qual(is) destino(s) você gostaria de visitar? Por quê? \\
\hline 9. & $\begin{array}{l}\text { Você já visitou um mesmo lugar mais de uma vez para praticar ecoturismo } \\
\text { ou turismo de aventura? Por quê? }\end{array}$ \\
\hline 10. & $\begin{array}{l}\text { Descreva em uma palavra o significado de viajar para fazer ecoturismo ou } \\
\text { turismo de aventura. }\end{array}$ \\
\hline
\end{tabular}

Fonte: Elaborado pelos autores. Source: Elaborated by the authors.

O público escolhido foi o de belo-horizontinos, de classe $A$ (renda familiar acima de $R \$ 9.745,00$ ) e $B 1$ (renda familiar entre $R \$ 4.963,00$ a $\mathrm{R} \$ 9.745,00$ de acordo com o critério Brasil (BRASIL, 2012c)) que já consomem esse tipo de serviço, isto é, pessoas que declararam ter viajado ao menos uma vez para destinos de ecoturismo e turismo de natureza. A 
escolha dos entrevistados também considerou o perfil predominante de ecoturistas, os quais possuem poder aquisitivo médio e alto, tem entre 25 e 30 anos e escolaridade de nível superior (BRASIL, 2008). Nesse sentido, os entrevistados (Quadro 2) foram escolhidos por conveniência, devido à facilidade de contato com os mesmos. Outros dois fatores que influenciaram a escolha do público entrevistado foram: a importância de Minas Gerais como emissor de turistas, representado pela capital Belo Horizonte, e a grande oferta de viagens de ecoturismo e turismo de aventura em Minas Gerais, em virtude da diversidade dos recursos naturais da região.

Foi feita uma entrevista piloto para verificação dos dados apresentados e após uma adaptação do questionário, novas entrevistas foram aplicadas face-a-face. As entrevistas aconteceram no mês de junho de 2013 e totalizaram 10 entrevistados, dentre homens e mulheres de 24 a 36 anos. A escolha do número de entrevistados foi baseada na saturação nas respostas das entrevistas, ou seja, as respostas começaram a ser similares ou iguais.

O roteiro utilizado para entrevistar o grupo pesquisado abordou 10 questões baseadas no modelo de Estímulo-Resposta do Comportamento do Consumidor de Middleton (1994) e nos fatores motivacionais para o comportamento de consumo no turismo, explicados por autores como Neiman, Geerdink e Pereira (2011) e Ross (2002), com enfoque no processo de decisório de compra.

Quadro 2: Quadro de entrevistados.

Table 2: Table of interviewees.

\begin{tabular}{cccc}
\hline ENTREVISTADO & GÉNERO & IDADE & ESCOLARIDADE \\
\hline E1 & Masculino & 25 & Superior completo \\
E2 & Masculino & 24 & Superior incompleto \\
E3 & Masculino & 24 & Superior incompleto \\
E4 & Feminino & 36 & Superior incompleto \\
E5 & Masculino & 36 & Pós-graduado \\
E6 & Masculino & 24 & Superior completo \\
E7 & Masculino & 23 & Ensino médio completo \\
E8 & Feminino & 22 & Superior completo \\
E9 & Masculino & 24 & Superior completo \\
E10 & Masculino & 25 & Superior completo \\
\hline
\end{tabular}

Fonte: Elaborado pelos autores. Source: Elaborated by the authors.

As respostas coletadas foram analisadas de acordo com as orientações de Creswell (2007). Primeiramente, os dados foram transcritos e organizados, depois foram lidos com o objetivo de encontrar pontos e ideias importantes para a pesquisa. Posteriormente, foi feita uma análise e codificação de determinadas frases ou trechos para que fosse possível agrupar determinados assuntos que fossem relevantes para a pesquisa. 
Após a análise da codificação dos grupos de entrevistados, foram estabelecidas relações entre as mesmas e o conteúdo da revisão bibliográfica, com enfoque nos fatores motivacionais relacionados ao consumo de turismo. A partir dessa análise, foram obtidos os resultados apresentados neste estudo.

\section{Resultados}

Fundamentado pelo modelo de Estímulo-Resposta de Middleton (1994), o presente estudo analisou os resultados da pesquisa, no que diz respeito aos principais fatores de motivação que levaram moradores de Belo Horizonte a adquirirem serviços e produtos relacionados ao ecoturismo e ao turismo de aventura.

\section{Entrada de Estímulo}

No primeiro processo do modelo de Middleton (1994), a entrada de estímulo, o autor menciona a competitividade do setor. Os entrevistados demonstraram que é grande oferta de destinos turísticos capazes de atender aos segmentos de ecoturismo e turismo de aventura. Diversos locais foram citados, tanto no Brasil quanto no exterior, ao serem questionados sobre destinos que gostariam de visitar.

"Vários [destinos]. No Brasil: nordeste, Amazônia e sertão. América do sul, Antártica, Fernando de Noronha." (ENTREVISTADO 3)

"Peru é o lugar que mais me atrai hoje em dia, por sua história, por conhecer Machu Pichu e pelas ondas incríveis que existem ali. O Chile é outro país que vou há anos fazer snowboard, acredito que as melhores estações de esqui da América do Sul estão ali e, por isso, meu desejo em estar sempre por perto. O Canadá é um país que nunca tive a oportunidade de conhecer, mas que certamente é um destino muito cobiçado pela infinidade de esportes radicais presentes ali. Nova Zelândia, Austrália, África do Sul, enfim, são muitos os lugares onde ainda desejo estar." (ENTREVISTADO 6)

O interesse pelos destinos a serem visitados está relacionado à imagem que se constrói acerca dos mesmos (MATHIESON; WALL, 1996). Considerando que há inúmeros destinos que podem satisfazer os desejos dos ecoturistas, é pertinente investigar porque alguns destinos se destacam em detrimento de outros. A imagem se forma através de informações provenientes de fontes como família, amigos e canais de comunicação e influencia diretamente a tomada de decisão do consumidor, justamente por ser uma das responsáveis pelo impulso de compra, que varia de acordo com cada indivíduo, já que está conectada às suas necessidades e desejos pessoais. De acordo com Chiu et al. (2013), a imagem do destino, a motivação e a atitude podem ser utilizadas para prever as intenções 
comportamentais de turistas que buscam um apelo ambiental. Ainda, mensurar a imagem do destino pode ser de grande valia para se comparar diferentes destinos (KRIDER et al., 2010), além de identificar os pontos fortes e fracos do local (LEE, 2009). Assim, o estímulo serve como gatilho para gerar 0 interesse do turista sobre o destino e iniciar a formação da imagem do mesmo pelo consumidor, que, futuramente, pode optar por visitar o destino de interesse.

\section{Canais de comunicação}

No segundo processo do modelo de Middleton (1994), "canais de comunicação", percebeu-se nas falas dos entrevistados a influência, sobretudo, dos grupos de referência, da família e dos amigos no comportamento do consumidor de ecoturismo e turismo de aventura.

"Comecei a fazer turismo de aventura aos 10 anos com pescas esportivas junto com meu pai e irmão. Depois comecei a fazer mochilões e outros tipos de viagem de aventura com amigos e poucas vezes sozinho" (ENTREVISTADO 1).

"Viajo acompanhada. Eu e meu marido gostamos muito de turismo de aventura. Nós nos influenciamos mutuamente" (ENTREVISTADO 4).

"Desde muito jovem estive imerso na cultura de esportes de aventura. Quando garoto, por volta dos 10 anos, meus pais sempre me levavam a lugares como a Serra do Cipó para fazer atividades de aventura na natureza" (ENTREVISTADO 6).

"Normalmente viajo acompanhado de amigos que são as principais influências para as viagens de aventura" (ENTREVISTADO 9).

As respostas mostram que normalmente as pessoas entrevistadas estão acompanhadas no momento de viajar, seja por um parente, um amigo ou um namorado. Esse resultado demonstra a influência social citada por Gilbert (1991), Churchill e Peter (2000) e Kotler (2006) para o processo de tomada de decisão, isto é, em caso de viagens compartilhadas a decisão depende de mais de um consumidor que possui poder de interferir na escolha dos produtos e serviços.

"Na grande maioria das minhas viagens com esse intuito estou acompanhado dos meus amigos e nós todos escolhemos os destinos, por isso, eles são os grandes influenciadores nas minhas decisões" (ENTREVISTADO $6)$.

"Normalmente viajo acompanhado dos meus amigos e são eles os meus maiores influenciadores nas escolhas das viagens" (ENTREVISTADO 7). 
A recorrência de respostas que relacionam o consumo de ecoturismo e turismo de aventura à família e a grupos de referência ressalta a importância da confiança em intermediários no momento da decisão de compra, apontada por Mathieson e Wall (1996) como um fator motivacional para o consumo.

Apesar da influência do ambiente de trabalho ter sido amplamente tratada no referencial teórico por Ross (2002) que trata do comportamento do consumidor em turismo, não foi possível percebê-lo nas entrevistas.

Durante a análise das entrevistas pôde-se também perceber a importância da internet para a divulgação ou propaganda conforme o modelo de Middleton (1994), das viagens de ecoturismo e turismo de aventura. A maioria dos entrevistados diz se informar a respeito de novas viagens através da internet. Esse resultado corrobora a pesquisa de BerginSeers e Mair (2009) que encontrou que a internet é a fonte de informação com maior tendência de ser utilizada por "turistas verde ${ }^{2 ",}$ em comparação com informações de agentes de viagem, jornais, amigos e família e centro de informações de visitantes.

"Atualmente minha maior fonte de informação tem sido um grupo de mochileiros no Facebook. Tem me ajudado muito também, o site dos mochileiros, onde as pessoas postam muitas dicas e tiram as dúvidas de quem pede ajuda" (ENTREVISTADO 8).

"As redes sociais, como o Facebook, são importantes meios de comunicação e é por lá que fico sabendo das novidades e bons destinos relacionados a essas espécies de viagens" (ENTREVISTADO 9).

"Através de blogs destinados a esse assunto e com minha agência de viagens" (ENTREVISTADO 10).

Pode-se atribuir a importância da internet durante o processo de decisão de compra dos entrevistados ao fato de que a mesma, enquanto mídia, também contribui para a formação da imagem acerca de determinado destino de viagem, fator motivacional identificado durante a revisão bibliográfica. Além disso, as informações de outros viajantes disponíveis em ferramentas de mídia social (como Facebook e blogs) são percebidas como mais atuais e confiáveis do que as informações de empresas turísticas (MIGUÉNS; BAGGIO; COSTA, 2008; YE; LAW; GU, 2009).

Promoção de vendas, folhetos, vendas particulares e relações públicas também fazem parte dos canais de comunicação do modelo de Middleton (1994), contudo, não foram citados pelos entrevistados. Esse resultado aponta para uma mudança no comportamento do consumidor de ecoturismo, que usa a internet para o planejamento de suas viagens.

Os dois primeiros processos do modelo Estímulo-resposta ("entrada de estímulo" e "canais de comunicação"), já citados e exemplificados se enquadram como processos de pré-compra. A seguir, serão expostos resultados relacionados ao processo de compra e pós-compra, que no 
modelo de Middleton (1994) se chamam: "características do comprador" e "processo de tomada de decisão", e "respostas de compra".

\section{Processo de tomada de decisão}

\section{Filtros de comunicação: aprendizado, percepções e experiência}

O processo "características do comprador e processo de tomada de decisão" divide-se em "filtros de comunicação" e "motivação". Os filtros de comunicação incluem o aprendizado, as percepções e a experiência do consumidor, que são influenciadas também pela experiência de póscompra. Foi possível perceber a influência de todos esses fatores na fala dos entrevistados.

O aprendizado surge em respostas que tratam de como o consumidor começou a viajar. Muitos dos entrevistados começaram a praticar o ecoturismo com sua família enquanto ainda eram crianças, e quando se tornaram adultos continuaram em busca do mesmo tipo de viagens. Outros entrevistados já praticavam esportes desde a infância e quando chegaram à idade adulta quiseram conciliar a prática de esportes às suas viagens de turismo:

"Na minha vida toda sempre pratiquei muitos esportes de todos os tipos e o esporte tem uma ligação muito grande com o turismo de aventura e o ecoturismo. O esporte que me levou a escolher esse tipo de viagem" (ENTREVISTADO 7).

"Desde os 12 anos meus pais sempre me levavam pra acampar e fazer trilha com eles acabei tomando gosto pela coisa" (ENTREVISTADO 8).

Desse modo, novamente o aprendizado vem influenciado por referências externas dos turistas, mas dependem também de um processo cognitivo e individual dos mesmos, isto é, trata-se de uma junção de influências culturais, sociais, pessoais e psicológicas conforme citam Engel, Blackwell e Miniard (2005).

As percepções dos consumidores estudados apareceram ao serem questionados para definir em uma palavra o ecoturismo ou turismo de aventura. A palavra que mais apareceu foi liberdade. Outras palavras que também surgiram foram: aventura, felicidade, prazer e lazer.

A percepção de liberdade pôde também ser identificada no momento de escolha por um pacote de turismo de aventura ou ecoturismo, ou mesmo de qualquer viagem independente. A resposta recorrente dos entrevistados foi a de que o desejo do consumidor é ter liberdade para fazer o que quiser no destino escolhido e a compra de um pacote de viagem limita os turistas.

Pode-se exemplificar essa situação através da fala dos entrevistados 3 e 4 diante da pergunta sobre a preferência de viajar através de uma agência de turismo: 
"Não, prefiro viajar com pessoas conhecidas que conhecem a região, assim tem-se maior liberdade de planejamento e mudança nos planos" (ENTREVISTADO 3)

"Não. Tenho a impressão que ela limita as possibilidades de aventura e das coisas acontecerem. Gosto também de participar do processo de pesquisa e escolha das coisas da viagem" (ENTREVISTADO 4)

A liberdade também foi citada como um importante fator de motivação relacionado à flexibilidade e foi explicada quando o entrevistado, que viaja para praticar um tipo de esporte que depende das situações climáticas, altamente variáveis, precisa de maior flexibilidade em suas viagens.

"Flexibilidade, que é um conceito que vai além de atendimento personalizado. Mas sim entender que em esportes de aventura as condições de tempo podem mudar em cima da hora e influenciar a prática de alguns esportes. Por isso acho favorável o uso de alguma estratégia que desse uma maior flexibilidade para os clientes" (ENTREVISTADO 2).

Ainda, fica nítida a interferência de fatores situacionais para o processo de tomada de decisão e compra dentro do destino turístico, uma vez que sazonalidade e clima podem interferir no processo.

Outros entrevistados preferiram viajar através de agências, pois dessa forma sentiam-se mais seguros e confortáveis. Essa percepção pode ser utilizada pelas agências para complementar os serviços oferecidos e também para planejamento interno e treinamento de equipes das empresas que prestam serviços relacionados ao turismo de aventura e ecoturismo. As percepções de segurança e comodidade podem ser exemplificadas pelas seguintes falas:

"Não costumo comprar pacotes, mas certamente para uma viagem em lugares desconhecidos e com práticas de atividades que trazem risco à vida a estrutura da operadora, capacitação dos guias, seguros e planos de mitigação de acidentes seriam levados em conta" (ENTREVISTADO 5).

"A segurança e o preço são os fatores mais importantes na escolha de um pacote de ecoturismo ou turismo de aventura (...), devido à comodidade e segurança proporcionados pela agência" (ENTREVISTADO 9).

"O mais importante é ter segurança de que estou adquirindo um serviço de qualidade, que não vai me trazer dor de cabeça durante a viagem" (ENTREVISTADO 10).

Os resultados sugerem que consumidores com mais de 30 anos mostraram-se mais dispostos a utilizar o serviço de uma agência de viagens para organizar seus passeios, desde que a mesma atenda às suas 
especificações, como segurança e conforto. Os resultados sobre a escolha por uma agência de viagem estão em conformidade com Muresan (2012), que também encontrou que pessoas acima de 30 anos possuem uma tendência maior de organizar viagens através de agências. Ademais, Muresan (2012) encontrou que jovens até 29 anos preferem organizar suas viagens de maneira independente. Esse resultado também corrobora Muresan (2012) na percepção de segurança dos consumidores. A autora justifica que a organização de viagem permeia o quanto o turista deseja se sentir seguro, em todos os serviços/ produtos ou em apenas algum deles.

A experiência do consumidor, presente no modelo estímulo-resposta foi um fator de influência percebido no momento de pós-compra, quando as expectativas dos consumidores foram atingidas.

O fato dos entrevistados retornarem, ou não, a um destino de ecoturismo está relacionado à influência da experiência de pós-compra durante o processo de tomada de decisão. Quando os entrevistados dizem ter voltado a visitar determinado local significa que as expectativas foram atingidas, levando a uma experiência agradável.

"Sim [eu visitei lugares mais de uma vez]. Porque minha experiência foi boa" (ENTREVISTADO 3).

"Tem lugares que passo que gosto muito que uma vez não é suficiente" (ENTREVISTADO 7).

"Sim, já visitei um mesmo local mais de uma vez para praticar ecoturismo principalmente pelo fato de ser um local onde pude apreciar as paisagens mais belas da minha vida e também devido à excelente hospedagem e estrutura do lugar" (ENTREVISTADO 9).

Ainda, conforme Lee (2009), a compra repetida se relaciona com a lealdade do consumidor e, por vezes, engloba uma atitude afetiva entre o turista e o destino visitado. Conforme os trechos dos entrevistados 3, 7 e 9 , é possível perceber uma resposta comportamental, já que Lee (2009) assume que o componente comportamental da atitude do turista é a indicação verbal da preferência do turista por um destino.

\section{Motivação - desejos, necessidades, objetivos e atitudes}

A outra parte do processo, "características do comprador e processo de tomada de decisão" inclui a motivação, e seus fatores influenciadores são: posição demográfica e socioeconômica, características psicográficas, desejos, necessidades, objetivos e atitudes. O levantamento de características socioeconômicas dos turistas não foi ênfase desta pesquisa já que foi feito um recorte para possibilitar a análise dos dados. Contudo, estudos como o da ABETA/BRASIL (2009) auxiliam na definição do perfil do consumidor de ecoturismo e turismo de aventura que, em geral, possuem entre 25 e 50 anos, poder aquisitivo médio e alto e escolaridade de nível superior. Ainda, Chaminuka et al. (2012) estimaram que há efeito da origem 
do turista (nacionalidade) e renda nas escolhas de compra de serviços em destinos de ecoturismo. As características psicográficas não puderam ser observadas nas entrevistas, pois não foram aplicados testes específicos com esse intuito.

Os "desejos", "necessidades", "objetivos" e "atitudes", presentes no modelo de Middleton (1994), podem ser encontrados na entrevista quando os consumidores foram questionados sobre a justificativa de escolher 0 turismo de aventura e/ou ecoturismo. Dentre as necessidades, desejos e objetivos foi possível identificar o interesse por contato com a natureza, prática esportiva em determinados locais e busca por lazer como fatores que despertam o interesse dos indivíduos entrevistados por viagens.

"O desejo de viajar surgiu, principalmente, a partir da vontade de conhecer locais diferentes. Existem vários locais paradisíacos devido à sua exuberante natureza nos quais o ecoturista pode satisfazer plenamente sua vontade de ter contato com o meio ambiente e os quais eu pretendo conhecer" (ENTREVISTADO 9).

"O contato com a natureza e a possibilidade de inserção em ambientes pouco afetados pela urbanização sempre me encantaram e sempre que posso procuro ir para locais onde consiga fazer o ecoturismo" (ENTREVISTADO 9).

"Emoção. Lembranças. Contato com a natureza. Adrenalina. Sensação de fazer algo diferente, emocionante e que fique na lembrança. Vivemos hoje no mito do 'aventurismo', talvez possa ser isso também. Ter a sensação de ser livre e aventureiro em um mundo fechado, restrito, com regras e etc." (ENTREVISTADO 3).

"O ecoturismo proporciona um maior contato com a natureza e com atividades que predispõe o indivíduo a aventurar-se em situações muitas vezes inusitadas" (ENTREVISTADO 4).

"Gosto de estar em contato com a natureza e sair do ambiente urbano" (ENTREVISTADO 5).

Entender a motivação do turista é um processo complexo e, geralmente, multifacetado (LEE, 2009). Uma das motivações mencionada por alguns entrevistados relacionaram a escolha de determinado local à prática de esporte. Assim, ressalta-se a forte relação entre esporte e turismo de aventura como fator motivacional para as viagens.

"Todas as viagens que faço são para áreas litorâneas que tenha surf. Por isso, no momento da escolha do lugar todas as informações em relação ao surf têm que estar junto comigo. Esse é o ponto principal e mais importante nas minhas escolhas e obtenho essas informações normalmente na internet e com conhecidos que já foram ao lugar" (ENTREVISTADO 7). 
“É uma maneira de conciliar o esporte com o lazer. Pelo fato de compartilhar com minha namorada o mesmo desejo, resolvemos sempre procurar por esse tipo de férias" (ENTREVISTADO 10).

Em relação às "atitudes" de consumo também foi possível perceber uma diferença quando o turismo de aventura ou ecoturismo acontece em localidades próximas ou destinos distantes. Quando a viagem é mais curta, não há muito planejamento prévio, e as decisões podem ser tomadas por impulso. As agências de turismo podem utilizar-se dessa informação para buscar atender seus possíveis clientes.

\begin{abstract}
"Existem viagens que demandam uma antecedência maior, como é o caso de viagens para o exterior, ou viagens que o tempo de ausência será maior. Nesse tipo de viagens geralmente me programo com 2 meses de antecedência. Entretanto, a grande maioria das viagens do meu dia-a-dia são planejadas e resolvidas em cima da hora, como uma semana antes" (ENTREVISTADO 6).
\end{abstract}

"Se é viagem internacional, normalmente, planejo com no mínimo 6 meses de antecedência. Dentro do Brasil não são todas as vezes que planejo" (ENTREVISTADO 7).

Sob outra perspectiva, Chaminuka et al. (2012) descrevem em seu estudo que as percepções dos turistas internacionais e domésticos são estatisticamente diferenciadas em destinos de ecoturismo, em relação à compra de produtos e serviços da comunidade local. Nesse sentido, há indicação teórica e empírica de que a cultura interfere na percepção do turista, desde o planejamento da viagem até a tomada de decisões e pós compra.

\title{
Respostas de compra
}

\section{Preço}

O último processo do modelo estímulo-resposta, "respostas de compra" apareceu de forma secundária na pesquisa, que enfatizou o processo decisório do turista de aventura e ecoturista. Alguns aspectos ressaltados pelos entrevistados foram a influência do preço e do produto. $O$ preço foi considerado quando os consumidores responderam o que levam em consideração ao decidirem por um pacote turístico.

"Sem dúvida a coisa mais importante ao analisar um pacote de ecoturismo é a relação custo-benefício. Nós, ainda jovens, nem sempre podemos fazer o programa que queremos devido aos preços elevados" (ENTREVISTADO $6)$. 
"Geralmente não viajo por pacotes, mas acontece de, no destino, para ir a determinado ponto ter que contratar um pacote. O que mais conta é o preço, normalmente vou ao mais barato" (ENTREVISTADO 8).

Muresan (2012) também afirma que os turistas são influenciados pelo preço, apesar de ter encontrado em sua pesquisa que alguns turistas pagariam mais por serviços de maior qualidade.

O produto foi um fator de influência que pôde se percebido quando os consumidores explicaram que escolhem determinada viagem de turismo devido às suas belezas naturais, que está relacionado à imagem que se tem de determinado lugar ou aos esportes oferecidos. O produto como já foi dito está relacionado também com o objetivo do consumidor, seja o contato com a natureza ou a prática de um determinado esporte na região.

"Chapadas brasileiras, Machu Pichu, Patagônia, Andes, Deserto de Sal. Devem ser lugares maravilhosos" (ENTREVISTADO 4, grifo nosso).

"Bem, atualmente, Bolívia, Chile e Peru, que já estou com viagem marcada. Principais motivos: Salar de Uyuni na Bolívia, deserto do Atacama no Chile e Machu Picchu no Peru, acho que são lugares incríveis e singulares" (ENTREVISTADO 8, grifo nosso).

Finalmente, o modelo de Middleton (1994) se mostrou uma ferramenta interessante e dinâmica para o entendimento dos fatores que interferem no comportamento do turista do segmento de aventura e ecoturismo. Também em contraste com a literatura (SOUSA, 2010; MERCE et al., 2012), fica subentendido na fala dos entrevistados que a preocupação com a sustentabilidade local dos destinos de interesse não é o principal enfoque dos turistas desse segmento. Assim, vale destacar a necessidade de estudos que permeiem o entendimento dos consumidores sobre a definição desse tipo de turismo e as (in)coerências entre pensamento e ação desses turistas, conforme apontado por Bergin-Seerse e Mair (2009).

\section{Considerações finais}

Foi possível identificar os principais fatores que influenciam 0 comportamento de compra para viagens de ecoturismo e turismo de aventura como: grupos de referência (família, amigos, namorados), ambiente onde o indivíduo está inserido e a imagem que o indivíduo tem de determinado destino. A busca por lazer e entretenimento, o interesse em práticas esportivas e o contato com o meio ambiente demonstraram ser os principais objetivos dos turistas entrevistados. Assim, questões relacionadas à sustentabilidade, à aprendizagem e ao apoio à comunidade local citadas por Merce et al. (2012) e Chaminuka (2012) parecem se apresentar em segundo plano no comportamento de turistas que buscam atividades de turismo de natureza e ecoturismo. 
A partir da identificação desses fatores, pode-se concluir que o consumo de ecoturismo e turismo de aventura está relacionado mais intimamente a duas das categorias motivacionais apontadas por Mclntosh, Goeldner e Richie (1995) os motivadores físicos (atividades, como esportes, que reduzem a tensão e promovem o relaxamento) e os motivadores culturais (desejo de explorar outras culturas e busca por novas experiências).

A "liberdade" também foi uma das principais características atribuídas ao ecoturismo e ao turismo de aventura. Palavras-chave ligadas às sensações provocadas pelo esporte também foram recorrentes como: adrenalina, prazer e felicidade. Todos esses fatores estão ligados à percepção que os consumidores têm desse tipo de serviço.

Percebe-se a complexidade do comportamento do consumidor no turismo, já que, apesar da existência de questões comuns a todos, cada consumidor possui expectativas específicas. Essas expectativas estão relacionadas à construção da imagem que cada indivíduo possui sobre a viagem que pretende fazer e devem ser atendidas ou superadas, para que futuramente o mesmo possa influenciar positivamente outros consumidores que tenham interesse no mesmo destino.

O estudo também mostrou que muitos consumidores desse tipo de serviço (ecoturismo e viagens de turismo de aventura) preferem organizar suas viagens de forma independente, sem a participação de agências de viagem, principalmente os consumidores mais jovens que acreditam que assim irão obter maior flexibilidade e liberdade. Os consumidores com mais de 30 anos mostraram-se mais dispostos a utilizar o serviço de uma agência de viagens para organizar seus passeios, desde que a mesma atenda às suas especificações, como segurança e conforto.

Sobre as implicações gerenciais, é importante que o mercado de turismo volte atenções para ações embasadas no marketing turístico, a promoção da imagem dos destinos e a oferta de produtos inovadores, tendo em vista as múltiplas oportunidades e a competitividade dos setores de ecoturismo e turismo de aventura nos níveis nacional e internacional.

Conforme Torres-Sovero et al. (2012), o ecoturismo pode impulsionar ferramentas estratégicas para reforçar programas de conservação ambiental. Contudo, para incrementar a eficiência do ecoturismo para o desenvolvimento sustentável, é preciso ações de planejamento e gestão mais contundentes por parte das organizações de destinos turísticos (TORRES-SOVERO et al., 2012). Ainda, o sucesso de negócios turísticos está associado com o nível que os gestores conhecem e consideram o comportamento dos consumidores em potencial (MURESAN, 2012).

As agências de turismo podem explorar a percepção de liberdade dos consumidores para buscar maior flexibilidade em sua oferta de serviços. Assim, a personalização dos roteiros de viagem, a oferta de pacotes com grupos reduzidos e com opções de tempo livre ou de roteiros extra durante a viagem, podem tornar os produtos de aventura e ecoturismo mais atraentes para os consumidores. 
Outro ponto que merece atenção das agências de viagem é a procura por parceiros e operadoras que priorizem a segurança de seus consumidores durante as atividades em contato com a natureza e esportes. As agências também podem buscar oferecer produtos que ofereçam segurança, como seguros de viagem e equipamentos que ofereçam maior segurança aos produtos, além de profissionais qualificados a fim de satisfazer essas preocupações.

Ainda, as agências de viagem devem usufruir melhor da busca de informações e planejamento de viagem através da internet. Assim, a internet pode servir como um elemento de aproximação e engajamento entre consumidores potenciais e prestadores de serviços.

Entende-se que este trabalho apenas abre portas para a continuidade de estudos sobre o comportamento do consumidor do segmento escolhido. Estudos futuros podem buscar a relação de grupos que praticam esportes e suas escolhas de viagens, além de identificar as diferenças entre os valores dos consumidores e as ações durante viagens de ecoturismo.

O estudo esbarrou em algumas limitações teóricas, já que os modelos foram criados há mais de vinte anos. Como o comportamento do consumidor é um assunto que se altera ao longo dos anos, é possível que modelos encontrados na literatura possam estar defasados. Esses modelos também foram criados com base em outros países e mercados, apontando para a necessidade de propor novos modelos de comportamento do turista brasileiro.

Também é primordial o desenvolvimento de mais pesquisas empíricas sobre o comportamento do consumidor de turismo e suas diferenças em relação a outros consumidores. Tais problemas foram identificados anteriormente por Swarbrooke e Horner (2002) e o presente estudo constata que a área merece maior investigação.

Vale também ressaltar que não é possível generalizar os resultados obtidos para todos os consumidores de pacotes de ecoturismo ou turismo de aventura, em função da escolha metodológica. A pesquisa qualitativa foi feita com um grupo específico e limitado, apesar de poder ser replicada em outros destinos emissores.

Finalmente, cabe o aprofundamento dos estudos acerca do comportamento do consumidor no turismo para conseguir entender as expectativas de cada indivíduo e satisfazê-las, buscando a fidelização dos clientes.

\section{Referências bibliográficas}

ABETA; BRASIL. Ministério do Turismo. Diagnóstico do turismo de aventura no Brasil. Belo Horizonte: VB Marketing e Negócios, 2009. 156 p.

BERGIN-SEERS, S.; MAIR, J. Emerging green tourists in Australia: Their behaviours and attitudes. Tourism and Hospitality Research, v. 9, n. 2, p. 109-119, abr. 2009. 
BRASIL. Ministério do Turismo. EBAPE/Núcleo de Turismo. Pesquisa anual de conjuntura econômica do turismo. 8 ed. Rio de Janeiro: Fundação Getúlio Vargas, 2012a. 82 p.

BRASIL. Ministério do Turismo. EBAPE/Núcleo de Turismo. Sondagem do consumidor: intenção de viagem. Rio de Janeiro: Fundação Getúlio Vargas, v. 6, n. 25, jan. 2013. 12 p.

BRASIL. Ministério do Turismo. FIPE. Caracterização e Dimensionamento do Turismo Doméstico no Brasil - 2010-2011. São Paulo: FIPE, 2012b. 157 p.

BRASIL. Ministério do Turismo. Secretaria Nacional de Políticas de Turismo, Departamento de Estruturação, Articulação e Ordenamento Turístico, Coordenação Geral de Segmentação. Turismo de Aventura: orientações básicas. Brasília, 2008. $56 \mathrm{p}$.

BRASIL. Secretaria de Assuntos Estratégicos. Perguntas e respostas sobre a definição da Classe Média, 2012c. 13 p.

CHAMINUKA, P. et al. Tourist preferences for ecotourism in rural communities adjacent to Kruger National Park: A choice experiment approach. Tourism Management, v. 33, n. 1, p. 168-176, fev. 2012.

CHIU, Y. T. H.; LEE, W. I.; CHEN, T. H. Environmentally responsible behavior in ecotourism: Antecedents and implications. Tourism Management, v. 40, n. 2014, p. 321-329, jun. 2013.

CHURCHILL, G. A.; PETER, J. Paul. Marketing: criando valor para o cliente. São Paulo: Saraiva, 2000. 649 p.

CRESWELL, J. W. Projeto de pesquisa: métodos qualitativos, quantitativos e misto. $2^{\mathrm{a}}$ ed. Porto Alegre: Artmed, 2007. 296 p.

ELENA-NICOLETA, U. Determining the profile of tourists in braşov starting from their starting from their consumption and buying behavior towards products offered by tourism agencies. Annals of the University of Oradea, Economic Science Series, v. 18, n. 4, p. 865-868, 2009.

ENGEL, J. F.; BLACKWELL, R. D.; MINIARD, P. W. Comportamento do consumidor. 8. ed. Rio de Janeiro: LTC, 2000. 606 p.

EWERT, A. Why people climb: the relationship of participant motives and experience level to mountaineering. Journal of Leisure Research, Urbana (USA), v. 17, n. 3, p. 241-250, 1985.

FENNELL, D. A. Ecotourism: an introduction. Sustainable Development, v. 7, n. 4, p. 204, nov. 1999.

GILBERT, D. C. An examination of the consumer decision process related to tourism. In: COOPER, C.P. Progress in Tourism, Recreation and Hospitality Management. London: Belhaven Press, 1991. (vol. 3)

GNOTH, J. Motivation and Expectation Formation. Annals of Tourism Research, v. 24, n. 2, p. 283-304, 1997.

HALL, C. M. Adventures sport and health tourism. In: WEILER, B.; HALL C.M. Special Interest Tourism. London: Belhaven Press, 1992. 224 p.

KOTLER, P. Administração de marketing. 12. ed. São Paulo: Pearson Prentice Hall, 2006. 752 p.

KRIDER, R. E. et al. Trait and image interaction. Annals of Tourism Research, v. 37, n. 3, p. 779-801, jul. 2010. 
LEE, T. H. A Structural Model to Examine How Destination Image, Attitude, and Motivation Affect the Future Behavior of Tourists. Leisure Sciences, v. 31, n. 3, p. 215-236, may 2009.

MALHOTRA, N. K. Pesquisa de marketing: uma orientação aplicada. 4. ed. Porto Alegre: Bookman, 2006. 720 p.

MATHIESON, A.; WALL, G. Tourism: Economic Physical and Social Impacts. London: Longman, 1996. $216 \mathrm{p}$.

MCINTOSH, R. W.; GOELDNER, C. R.; RITCHIE, J. B. Tourism, Principles, Practices, Philosophies. New York: Wiley, 1995. 544 p.

MERCE, I. I. et al. Study on development and trends of ecotourism in Romania. Agricultural Management / Lucrari Stiintifice Seria I, Management Agricol, v. 14, n. 4, p. 351-356, 2012.

MIDDLETON, V.T.C. Marketing for Travel and Tourism. London: ButterworthHeinemann, 1994. 487 p.

MIGUÉNS, J.; BAGGIO, R.; COSTA, C. Social media and Tourism Destinations: TripAdvisor Case Study. In: ADVANCES IN TOURISM RESEARCH, 2008, Aveiro, Portugal. Anais... Aveiro: 2008. p.1-6.

MOUTINHO, L. Consumer Behaviour in Tourism. European Journal of Marketing, v. 21, n. 10, p. 5-44, 1987.

MOWFORTH, M. Eco-tourism: terminology and definitions. University of Plymouth, Department of Geographical Sciences, 1993. Research Report Series, n. 1.

MUREŞAN, D. M. The Behavior Of Tourist Services Consumer. Agricultural Management / Lucrari Stiintifice Seria I, Management Agricol, v. 14, n. 4, p.183188. 2012.

NEIMAN, Z.; GEERDINK, S.; PEREIRA J. C. A imagem como agente motivador para o ecoturismo. Revista Turismo em Análise, v. 22, n.1, p. 71-95, abr. 2011.

PIRES, S. A. DIMENSÃO CONCEITUAL DO ECOTURISMO. Turismo - Visão e Ação, v.1, n.1, p.75-91 jan-jun. 1998.

ROSS, G. F. Psicologia do turismo. 2. ed. São Paulo: Contexto, 2002. 174 p.

SCHMOLL, G. A. Tourism Promotion. London: Tourism International Press, 1977. $136 \mathrm{p}$.

SOUSA, B.; SIMÕES, C. Comportamento e perfil do consumidor de turismo de nichos. Revista de Estudos Politécnicos. v. 8, n. 14, p. 137-146, 2010.

SWARBROOKE, J., C. BEARD, S. LECKIE; G. POMFRET. Adventure Tourism: The New Frontier. Burlington, MA: Butterworth Heinemann, 2003.

SWARBROOKE J.; HORNER, S. O comportamento do consumidor no turismo. São Paulo: Aleph, 2002. $408 \mathrm{p}$.

TORRES-SOVERO, C. et al. Social-ecological factors influencing tourist satisfaction in three ecotourism lodges in the southeastern Peruvian Amazon. Tourism Management, v. 33, n. 3, p. 545-552, jun. 2012.

WAHAB, S.; CROMPTON, L. J.; ROTHFIELD, L. M. Tourism Marketing. London: Tourism International Press, 1976. 273 p.

YE, Q.; LAW, R.; GU, B. The impact of online user reviews on hotel room sales. International Journal of Hospitality Management, n. 28, p.180-182, mar. 2009. 


\section{Notas:}

${ }^{1}$ Artigo derivado de Monografia apresentada à Faculdade de Ciências Econômicas da Universidade Federal de Minas Gerais, como requisito à obtenção de título no Bacharelado em Administração.

${ }^{2}$ De acordo com Bergin-Seers e Mair (2009), o consumidor verde é descrito como aquele que busca proteger a si mesmo e ao mundo através do poder de compra.

Leandro Augusto Gouveia: Universidade Federal de Minas Gerais, Belo Horizonte, MG, Brasil.

E-mail: gouveia.leandro@hotmail.com

Marlusa Gosling: Universidade Federal de Minas Gerais, Belo Horizonte, MG, Brasil.

E-mail: mg.ufmg@gmail.com

Link para o currículo Lattes: http://lattes.cnpq.br/9503365193492380

Mariana de Freitas Coelho: Universidade Federal de Minas Gerais, Belo Horizonte, MG, Brasil.

E-mail: marifcoelho@gmail.com

Link para o currículo Lattes: http://lattes.cnpq.br/6529509228250270

Gisele de Araujo Pereira: Universidade Federal de Minas Gerais, Belo Horizonte, MG, Brasil.

E-mail: giseleap@gmail.com

Link para o currículo Lattes: http://lattes.cnpq.br/8695241335205649

Data de submissão: 25 de fevereiro de 2014

Data de recebimento de correções: 30 de junho de 2014

Data do aceite: 03 de julho de 2014

Avaliado anonimamente 